\title{
Optical dating of a sedimentary sequence in a trenching site on the source fault of the 1999 Chi-Chi earthquake, Taiwan
}

\author{
Yue-Gau Chen ${ }^{\mathrm{a}, *}$, Ya-Wen Chen ${ }^{\mathrm{a}}$, Wen-Shan Chen ${ }^{\mathrm{a}}$, Kun-Jie Lee ${ }^{\mathrm{a}}$, Long-Sheng Lee ${ }^{\mathrm{a}}$, \\ Shih-Ting Lu ${ }^{b}$, Yuan-Hsi Lee ${ }^{c}$, Takuya Watanuki ${ }^{a}$, Yu-Nung N. Lin ${ }^{\mathrm{a}}$ \\ ${ }^{a}$ Department of Geosciences, National Taiwan University, No. 1, Sec. 4th, Roosevelt Road, Taipei 106, Taiwan, ROC \\ ${ }^{\mathrm{b}}$ Central Geological Survey, Taipei, Taiwan, ROC \\ ${ }^{\mathrm{c}}$ Department of Earth and Environment Science, National Chung-Cheng University, Chiayi, Taiwan, ROC
}

Available online 18 January 2009

\begin{abstract}
A trenching site was excavated for the purpose of paleoseismic exploration and slip-rate acquisition along the Chelungpu fault, the source fault for the 1999 Chi-Chi earthquake (Mw 7.3) in central Taiwan. In previous studies that used conventional and AMS radiocarbon dating, sample ages clustered in three unevenly spaced groups: $<400,1700-2200$, and $>30000 \mathrm{BP}$. Those prior studies also yielded questionable long-term slip rates: the rate for the last $2 \mathrm{ka}$ was six times higher than the average for the past $40 \mathrm{ka}$. In order to reevaluate the time frame for this trench, optically stimulated luminescence (OSL) dating was applied. The large- and small-aliquot dose distributions were used to investigate the completeness of bleaching on nearby collected modern samples. Results indicate that the 5\% minimum ages derived from the small-aliquot dose distributions are preferable for dating young samples, which may include unbleached sediment grains associated with the incompletely bleached sediments. The final OSL dates indicate that the previously published radiocarbon ages include some incorrect ages resulting from contamination and reworking of deposits, and a revised time frame is presented. Cumulative vertical slip independently derived from trench log restoration is $1.8 \mathrm{~m}$ in the past 2000 years, which is consistent with the vertical slip rate, i.e., $0.91 \mathrm{~m} / \mathrm{ka}$, calculated from the depositional rate in the footwall. This result inversely suggests that the time frame presented in this study is reliable.
\end{abstract}

(C) 2009 Elsevier Ltd and INQUA. All rights reserved.

\section{Introduction}

The island of Taiwan started to form 6 million years ago by arc-continent collision between the Eurasian continental plate and the Philippine Sea plate. This tectonic process continues today (Fig. 1a; Ho, 1988; Teng, 1990). Under this regime, active faults developed and are distributed over the entire island (Bollina, 1975, 1977; Lin et al., 2000). Some of these faults are believed to generate large earthquakes. One example is the Chelungpu fault in central Taiwan, whose rupture caused the 1999 Chi-Chi earthquake (Mw = 7.3; CGS, 1999; Ma et al., 1999; Y.G. Chen et al., 2001; Shyu et al., 2005; Fig. 1b). This disastrous

\footnotetext{
*Corresponding author. Tel.: + 886223697648 ; fax: + 886223644625 . E-mail address: ygchen@ntu.edu.tw (Y.-G. Chen).
}

event caused over 2300 fatalities, 10,000 collapsed houses, and enormous economic losses.

For the purpose of mitigating the hazards posed by future large earthquakes, it is important to assess the recurrence intervals and the long-term slip rates of the relevant seismogenic faults. This is particularly important in western Taiwan due to its high population density. A reliable numerical chronology for past earthquakes plays a primary role in achieving this objective. The radiocarbon dating method has long been one of the most popular dating techniques, but in these environments its accuracy is often limited by discontinuous sample distribution and by reworking of deposits (e.g. W.S. Chen et al., 2004). The present study applies optically stimulated luminescence (OSL) dating to reanalyze a previously published sequence for paleo-earthquakes in a trenching site on the Chelungpu fault, where the chronology was previously 


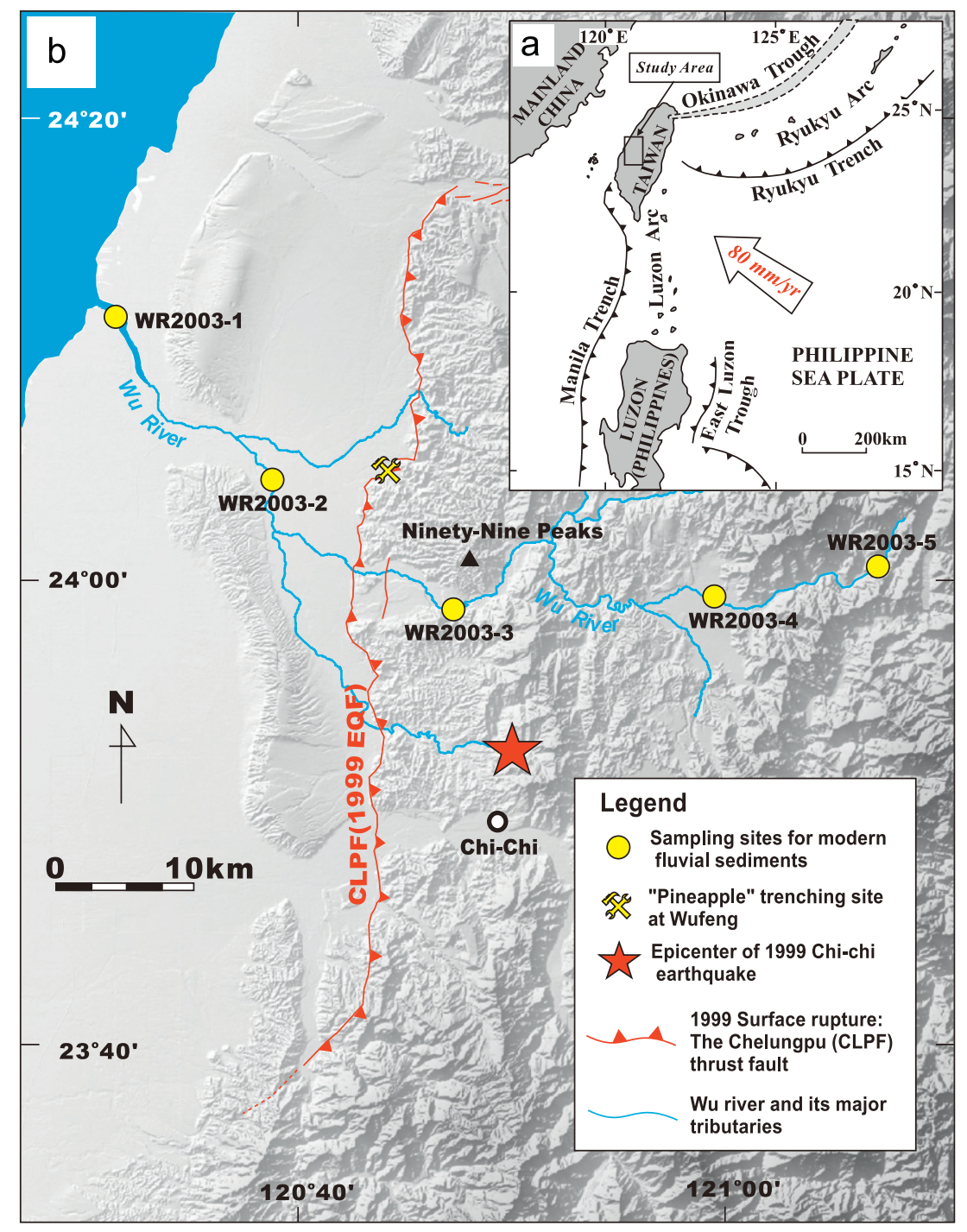

Fig. 1. (a) Map showing current tectonic environments surrounding Taiwan. (b) Map showing the foreland of western Taiwan and the location of the Chelungpu thrust fault. Yellow circles indicate the sampling sites of modern fluvial sediments along the Wu River.

based on radiocarbon dating (Fig. 2; Chen et al., 2003; W.S. Chen et al., 2004).

\section{Paleoseismological study and existing chronology}

Trenching across an active fault has been regarded as an effective way to retrieve key data about past fault behavior such as long-term slip rate, event slip, rupture behavior, and recurrence intervals (e.g. Sieh, 1984). Since the 1999 Chi-Chi earthquake, numerous trenching projects have been launched along the surface ruptures to investigate these parameters for the Chelungpu fault (W.S. Chen et al., 2001a, b, 2004, 2005, 2007; Y.G. Chen et al., 2001). One of these sites, "Pineapple", located on the central segment and showing clear coseismic deformation (Fig. 2; Y.G. Chen et al., 2003; W.S. Chen et al., 2004), was expected to give abundant information. However, radiocarbon dating at this site has not lead to a satisfactory reconstruction of the sedimentary sequence. Except for one very young date
(0.15-0.43 ka), all the other 11 conventional and AMS radiocarbon dates form two age clusters with ages of 1700-2200, and $>30,000$ BP (Fig. 2). Regardless of the reliability of these dates, two chronological problems are posed. The first is: why are dates from this trench concentrated in two groups? Are there only two, widely separated depositional phases in the footwall? Secondly, why is the derived long-term slip rate for the past $40 \mathrm{ka}$ (ca. $1.5 \mathrm{~mm} / \mathrm{a}$ ) much lower than during the past $2 \mathrm{ka}$ $(>8.6 \mathrm{~mm} / \mathrm{a})$. The latter rate is derived from the offset observed in the trench, while the former rate is estimated from the offset between the hanging wall and a nearby borehole independently drilled in the footwall (W.S. Chen et al., 2004). Is this huge difference the result of an increase in stress during the past several thousand years? Or it is merely the product of inaccurate age determinations? The starting hypothesis for this study was that the previously published radiocarbon ages are inaccurate due to contamination and reworking of the deposits. This work aims at 


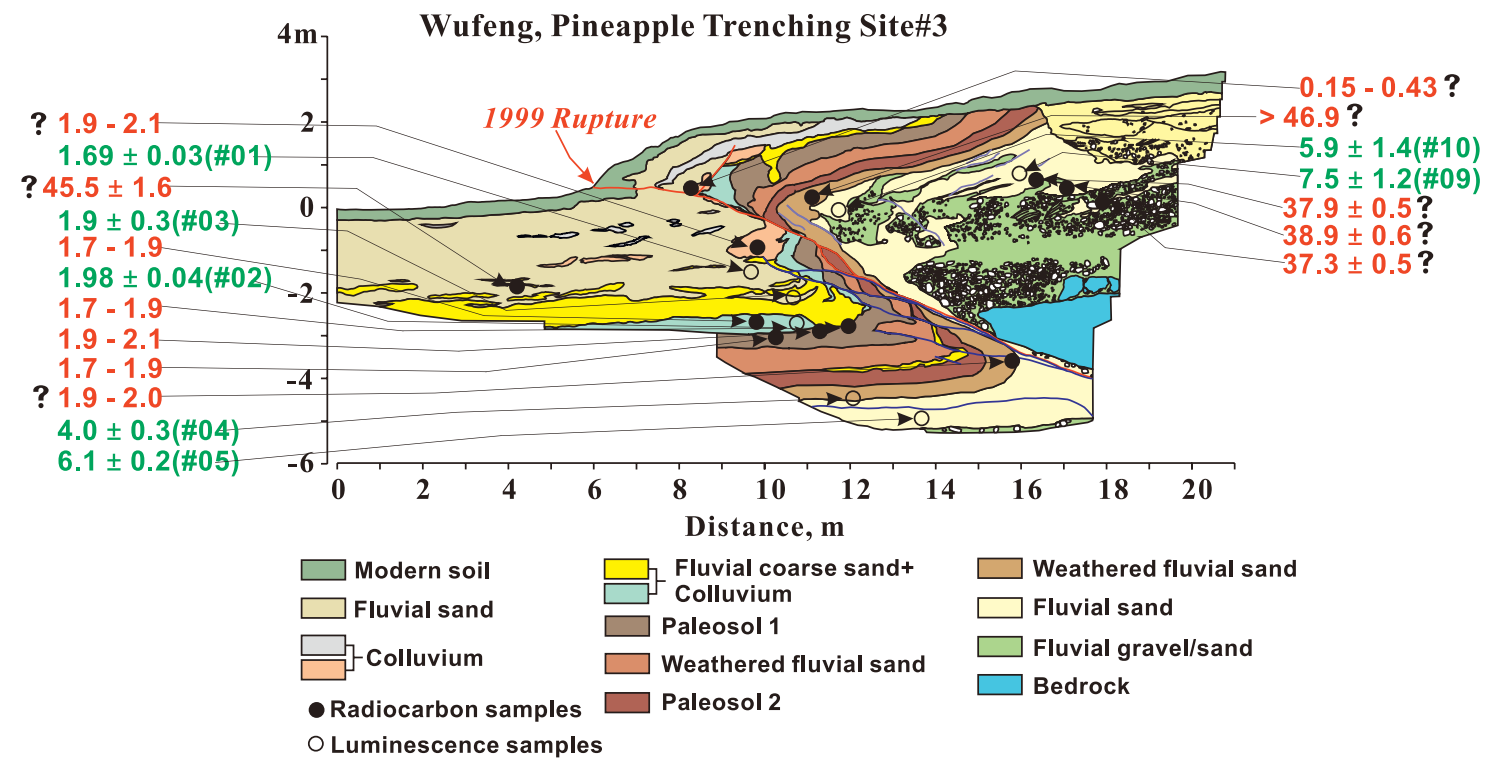

Fig. 2. Trench log of Pineapple site at Wufeng (see Fig. 1 for the location). The 1999 fault trace and older traces are given as red and blue lines, respectively. Previously published radiocarbon ages are shown in red and the OSL ages from this study in green with sample number between brackets (i.e., sample number here is the last two digits of those in Table 2). Those radiocarbon ages that are considered unreliable are marked with a question mark.

establishment of a more reliable chronology for these deposits and clarifying the ambiguities described above.

\section{Luminescence dating}

The OSL samples were collected by inserting PVC plastic tubes into sediment layers. To avoid further light influence, the ends of the tube were sealed until the samples arrived at the laboratory. The samples were opened in laboratory dark room conditions and the material from the outer ends of the tubes, which may have been exposed to daylight, was removed. The inner material was treated with $\mathrm{HCl}$ and $\mathrm{H}_{2} \mathrm{O}_{2}$ to remove carbonates and organic material and then sieved to isolate the fraction of $90-125 \mu \mathrm{m}$. This fraction was etched with $40 \%$ HF for $1 \mathrm{~h}$ to obtain a pure quartzrich extract. The quartz-rich extract was considered to be sufficiently pure when the infrared stimulated luminescence (IRSL) to blue-light stimulated luminescence (BLSL) ratio measured at a preheat temperature of $220^{\circ} \mathrm{C}$ for $10 \mathrm{~s}$ was less than 0.1 . Up to this step, the grains were presumably dominated by quartz, although the outer rims have been removed during HF etching. The quartz grains were attached to a $10-\mathrm{mm}$ stainless-steel disk using silicon oil. Large $(8 \mathrm{~mm})$ and small $(3 \mathrm{~mm})$ aliquots contained ca. 1000 and 200 grains, respectively. The OSL of each aliquot was measured by a Risø TL/OSL DA-15 reader, using blue LEDs for stimulation and a U-340 filter as the detection window. Before OSL reading to determine the equivalent dose $(D e)$, preheat plateau tests were applied for both modern and old samples (Figs. 3 and 4). Most of the recuperation tests gave satisfactory results, but the modern sample WR2003-1 yielded a recuperation increase at a temperature lower than $220^{\circ} \mathrm{C}$ during the thermal transfer test (Fig. 3b). Therefore, $220^{\circ} \mathrm{C}$ is considered as the preheat temperature for all samples in this study. The thermal transfer of modern samples at $220^{\circ} \mathrm{C}$ shows a dose of $0.38 \pm 0.01 \mathrm{~Gy}$ (Fig. 3b). The decay curve shows no other visible components except for the fast component. The thresholds for eliminating the aliquot are recuperation larger than $5 \%$, and recycling ratio out of the range of 0.9-1.1 (e.g. Fig. 3). For modern samples, those having an uncertainty on the natural test dose (i.e., photon-counting statistics) over $15 \%$ were eliminated (Thomsen et al., 2003). The dose rate of each sample is derived from chemical concentrations of $\mathrm{U}, \mathrm{Th}, \mathrm{K}$, and estimation of cosmic ray flux (Aitken, 1985). The chemical concentrations of $U$ and Th were determined with ICPMS, and the concentration of $\mathrm{K}$ by XRF. The water contents adopted are the values measured immediately after the samples arrived in the laboratory. However, for the borehole samples the saturated water contents are used instead because drilling occurred some months before sample collection.

\section{Modern fluvial samples}

Because the origin of the sediments in the trench has been identified as partly fluvial and partly colluvial (Fig. 2), the completeness of resetting of the sediment grains during transport needs to be tested. For this purpose, five modern samples were collected in 2003 from the Wu River at intervals of $15-20 \mathrm{~km}$, upstream from the littoral zone (Fig. 1b). In 2001, typhoon Toraji attacked central Taiwan, causing serious debris flows in the middle reach of the river at Ninety-Nine Peaks (Fig. 1b). Such an event may have brought a significant amount of unbleached sediment grains into the river at this location. The first round of testing involved large-aliquot measurements using the SAR protocol (Murray and Wintle, 2000), and yielded mean 
A

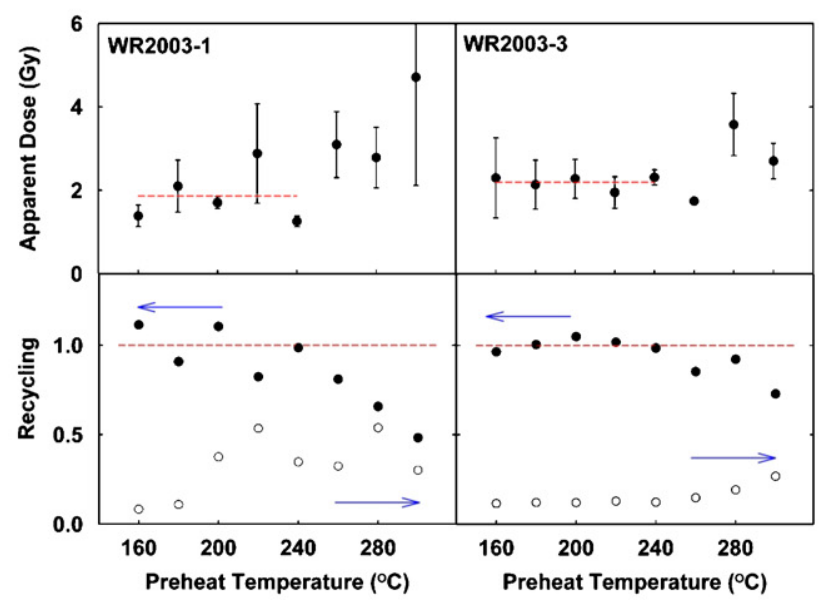

B

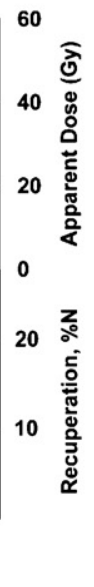

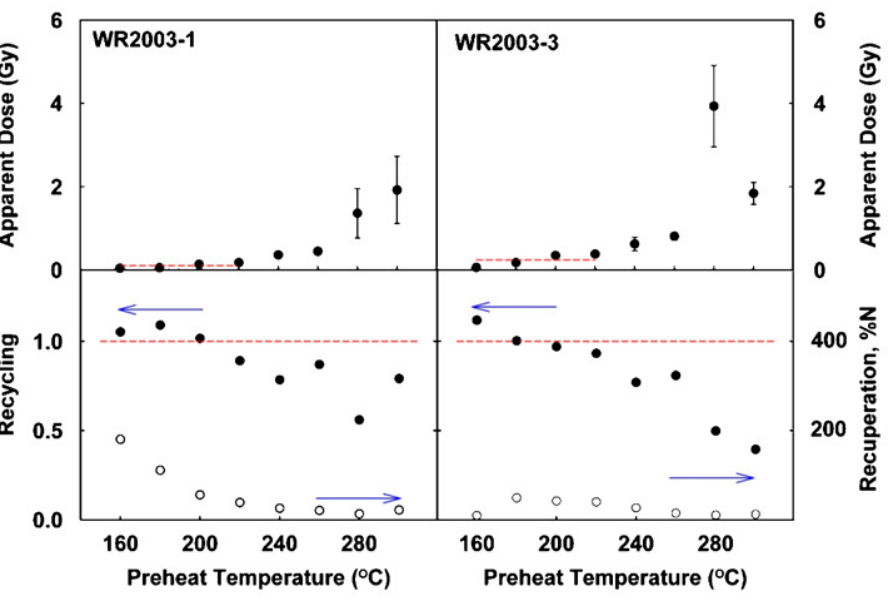

Fig. 3. The preheat plateau (A) and thermal transfer (B) tests for the samples of WR2003-1 and WR2003-3 collected from modern riverbeds. The recycling ratios are roughly kept around $1.0 \pm 0.1$ if the preheat temperature is lower than $240{ }^{\circ} \mathrm{C}$. However, for sample WR2003-1 the recuperation at the preheat temperature of $220^{\circ} \mathrm{C}$ is the best choice.

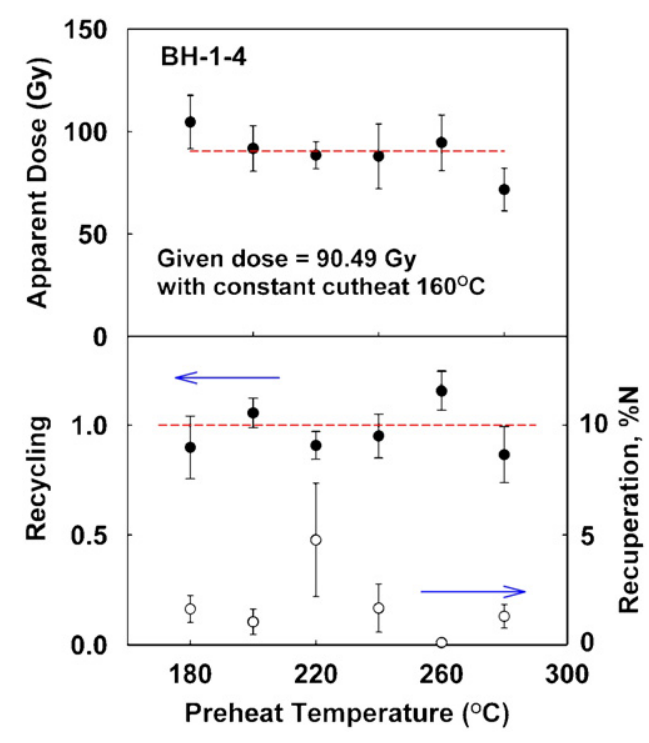

Fig. 4. Eighteen aliquots of sample BH-1-4 were separated into six groups to test the dose recovery under different preheat temperatures. The dose recovery is stable between preheat at 200 and $260^{\circ} \mathrm{C}$. All the aliquots are bleached twice by blue LED $(470 \mathrm{~nm})$ for $1000 \mathrm{~s}$ and given a known dose based on the total-mean value for this samples.

equivalent doses in all available aliquots (Table 1). All samples showed significant natural OSL intensities, especially the two samples from the middle reach (WR2003-2 and WR2003-3, Fig. 1b). For these two samples, the residual dose values can probably be attributed to the influx of unbleached grains during the 2001 debris-flow event (Fig. 5). Tentatively taking the averaged dose rate previously worked out in western Taiwan (i.e., $2.52 \pm 0.44 \mathrm{~Gy} / \mathrm{ka}$; Y.G. Chen et al., 2003; Y.W. Chen et al., 2003), the residual OSL can be converted into an age range of $670-10,000$ years. This strongly suggests that quartz OSL dating using large aliquots containing several thousands of grains is not applicable for dating young sediments in such a poorly bleached environment. According to previous work by Olley et al. $(1998,1999)$, the mean dose of the lowest $5 \%$ De values of a small-aliquot dose distribution may yield a dose close to the true burial dose of the well-bleached grains in a poorly bleached sample. However, this approach becomes inapplicable for older samples because the proportion of unbleached signal decreases as burial time increases.

This study determined the $5 \%$ minimum age only for young samples. The judging criterion to select the young samples will be discussed later in the text. Therefore, the second round of analyses repeated the measurements using small aliquots for all samples and obtained 5\% minimum De values (Table 1; Fig. 5). The mean and 5\% minimum De values are both substantially lowered when compared to the first round. In particular, the coastal sample (WR2003-1) shows a relict dose of only about $0.27 \mathrm{~Gy}$. However, the middle reach samples (WR2003-2 and WR2003-3) still yielded $D e$ values of 3.3-8.6 Gy, roughly equivalent to an age of 1000-3000 years. Considering that the debris source of the Ninety-Nine Peaks landslides exists only in the middle reach, these samples may be related to the debris event in 2001. The small-aliquot technique and minimum $5 \%$ age is a useful strategy to derive more reliable depositional ages if the sample contains relatively small contributions from rapid surface deposition.

\section{OSL ages}

\subsection{Pineapple trench}

Because the sedimentary facies identified in the "Pineapple" trench consists mainly of fluvial deposits, the modern sample results described above necessitate caution in interpreting the data, due to possible contributions of unbleached quartz grains from debris flows. For the purpose of comparison, both total-mean and $5 \%$ minimum 
Table 1

Equivalent dose values of modern fluvial sediments collected along the Wu River.

\begin{tabular}{|c|c|c|c|c|}
\hline \multirow[t]{2}{*}{ Sample code } & \multirow[t]{2}{*}{ Location X/Y (TWD67 $\left.{ }^{\mathrm{a}}\right)$} & \multicolumn{2}{|c|}{ Equivalent dose $^{\mathrm{b}}$ (Gy) } & \multirow[t]{2}{*}{ Number of aliquots } \\
\hline & & Mean (all) & Mean (minimum 5\%) & \\
\hline \multirow[t]{2}{*}{ WR2003-1 } & \multirow[t]{2}{*}{$199360 / 2676575$} & $1.6 \pm 0.2(\mathrm{~S})$ & $0.27 \pm 0.02(\mathrm{~S})$ & $46(\mathrm{~S})$ \\
\hline & & $1.7 \pm 0.2(\mathrm{~L})$ & $0.41 \pm 0.09(\mathrm{~L})$ & $44(\mathrm{~L})$ \\
\hline \multirow[t]{2}{*}{ WR2003-2 } & \multirow[t]{2}{*}{$212700 / 2660710$} & $14.1 \pm 1.6(\mathrm{~S})$ & $3.3 \pm 0.1(\mathrm{~S})$ & $48(\mathrm{~S})$ \\
\hline & & $10.4 \pm 1.0(\mathrm{~L})$ & $3.3 \pm 0.1(\mathrm{~L})$ & $45(\mathrm{~L})$ \\
\hline \multirow[t]{2}{*}{ WR2003-3 } & \multirow[t]{2}{*}{$227005 / 2653440$} & $23.8 \pm 2.0(\mathrm{~S})$ & $8.6 \pm 0.4(\mathrm{~S})$ & $48(\mathrm{~S})$ \\
\hline & & $25.2 \pm 1.8(\mathrm{~L})$ & $9.1 \pm 0.8(\mathrm{~L})$ & $47(\mathrm{~L})$ \\
\hline \multirow[t]{2}{*}{ WR2003-4 } & \multirow[t]{2}{*}{$246525 / 2653650$} & $6.3 \pm 1.0(\mathrm{~L})$ & $0.25 \pm 0.05(\mathrm{~S})$ & $19(\mathrm{~S})$ \\
\hline & & & & $12(\mathrm{~L})$ \\
\hline \multirow[t]{2}{*}{ WR2003-5 } & \multirow[t]{2}{*}{$261125 / 2656525$} & $4.6 \pm 0.9(\mathrm{~L})$ & $0.8 \pm 0.1(\mathrm{~S})$ & $21(\mathrm{~S})$ \\
\hline & & & & $12(\mathrm{~L})$ \\
\hline
\end{tabular}

${ }^{\text {a }}$ TWD67 is Taiwan grid, which is used in topographic maps published before 1999 .

${ }^{\mathrm{b}} \mathrm{S}$, small aliquot; L, large aliquot.
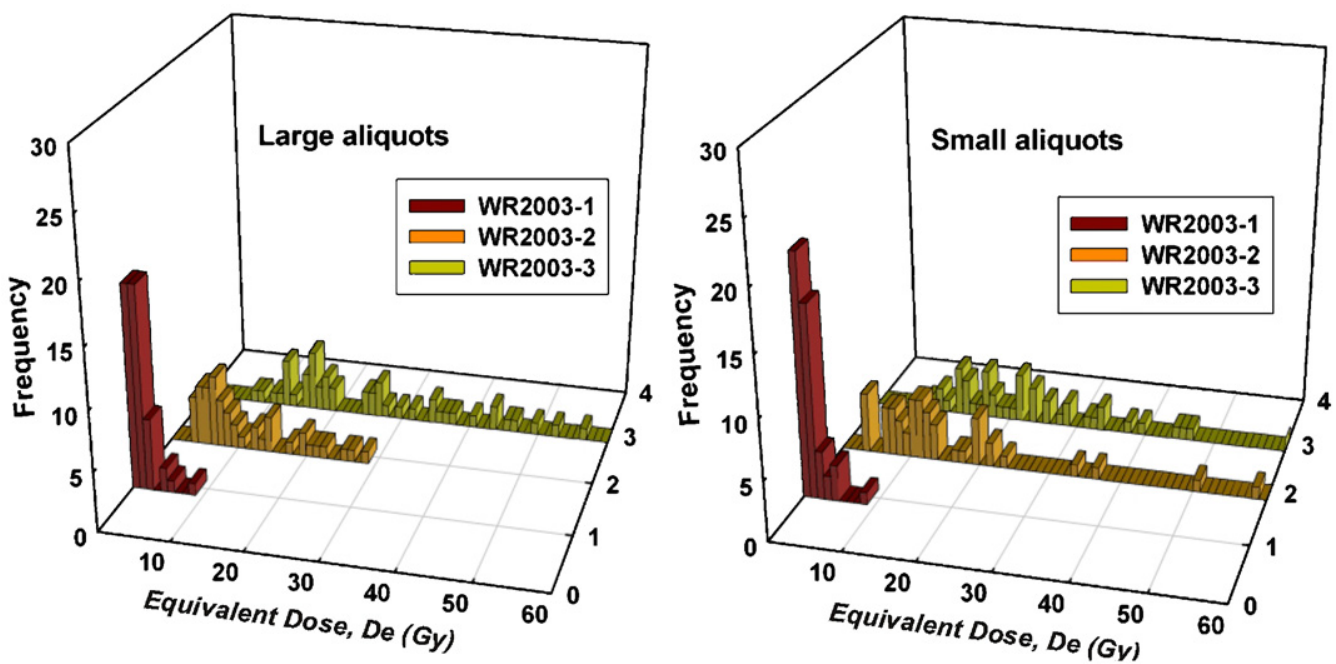

Fig. 5. Large- and small-aliquot dose distributions of three modern fluvial sediments from the Wu River.

ages of small aliquot for the samples collected in the trench were determined (Table 2). An age of paleosol \#1 has been previously determined as $1.9-2.1 \mathrm{ka}$ by radiocarbon dating (Fig. 2). This age is believed reliable, not only because of three consistent radiocarbon ages (the ages in red presented in the left of Fig. 2) but also that of another wood sample (1.4-1.7 ka; Y.G. Chen et al., 2003) that was collected on the top of this layer. The OSL ages obtained by total-mean method were clearly overestimates (Table 2 and Fig. 2). The ages of minimum $5 \%$ of small aliquots, on the other hand, appear to be accurate. The new minimum $5 \%$ ages allowed identification of unreliable radiocarbon dates. In the hanging wall, the fluvial sandy layers were actually deposited in the Holocene rather than the late Pleistocene, as had been suggested by the original radiocarbon dates. This indicates that the radiocarbon ages of $30-40 \mathrm{ka}$ or older are all spurious products of reworking. They may be derived from the Pliocene Chingshui Shale, which is distinguishable due to significant consolidation and contains abundant driftwood deposited with the coastal muddy sediments. The youngest radiocarbon age of $0.15-0.43 \mathrm{ka}$ in the uppermost part of the hanging wall is most likely the result of contamination with present-day carbon from roots that have penetrated this layer. With regard to the footwall, the upper two radiocarbon ages are definitely the products of reworking. The younger one (1.9-2.1 ka from the pink colluvium) is believed to represent material that was brought up by thrust faulting, possibly in association with the penultimate event. The older one (>45 ka) must come from the bedrock, as discussed above. Furthermore, the radiocarbon age of $1.9-2.0 \mathrm{ka}$ collected in the deepest part of the section is presumably derived on material from a fossil root.

The uppermost $2.5 \mathrm{~m}$ of the footwall consists of fluvial sediments deposited in the past $2 \mathrm{ka}$. The underlying darker layers, ca. $2.0 \mathrm{~m}$ thick, are soil layers developed at around $2 \mathrm{ka}$, but the parent materials were deposited somewhat earlier. The bottom of the footwall consists of fluvial sediments, deposited after $6 \mathrm{ka}$. On the other hand, the hanging wall is composed not only of the same units as of 
Table 2

Summary of dosimetric information, De values (all, minimum 5\%) and OSL ages for the samples from the "Pineapple" trenching site and borehole.

\begin{tabular}{|c|c|c|c|c|c|c|c|c|c|}
\hline $\begin{array}{l}\text { Sample } \\
\text { code }\end{array}$ & $\begin{array}{l}\text { Depth }^{\mathrm{a}} \\
(\mathrm{m})\end{array}$ & $\begin{array}{l}\mathrm{U}^{\mathrm{b}} \\
(\mathrm{ppm})\end{array}$ & $\begin{array}{l}\mathrm{Th}^{\mathrm{b}} \\
(\mathrm{ppm})\end{array}$ & $\begin{array}{l}\mathrm{K}^{\mathrm{b}} \\
(\%)\end{array}$ & $\begin{array}{l}\text { Estimated water } \\
\text { content }(\%)\end{array}$ & $\begin{array}{l}\text { Total dose } \\
\operatorname{rate}^{\mathrm{b}}(\mathrm{Gy} / \mathrm{ka})\end{array}$ & $\begin{array}{l}\text { Number of } \\
\text { Aliquots }\end{array}$ & $\begin{array}{l}D e(\mathrm{~Gy}) 5 \% \\
\text { minimum mean/total } \\
\text { mean }\end{array}$ & Age (ka) \\
\hline
\end{tabular}

\begin{tabular}{|c|c|c|c|c|c|c|c|c|c|}
\hline \multicolumn{10}{|l|}{ Trenching site } \\
\hline 20010302-01 & $1.5(\mathrm{FW})$ & 2.62 & 12.68 & 1.68 & 6 & 2.95 & 65 & $5.0 \pm 0.1 / 14.5 \pm 1.0$ & $1.69 \pm 0.03 / 4.9 \pm 0.3^{\mathrm{d}}$ \\
\hline 20010302-02 & $2.8(\mathrm{FW})$ & 2.36 & 10.84 & 1.58 & 5 & 2.71 & 73 & $5.4 \pm 0.1 / 11.9 \pm 0.9$ & $1.98 \pm 0.04 / 4.4 \pm 0.3^{\mathrm{d}}$ \\
\hline 20010302-03 & $2.1(\mathrm{FW})$ & 2.05 & 8.98 & 1.49 & 1 & 2.54 & 37 & $4.8 \pm 0.7 / 18.2 \pm 2.1$ & $1.9 \pm 0.3 / 7.2 \pm 0.8^{\mathrm{d}}$ \\
\hline 20010302-04 & $4.4(\mathrm{FW})$ & 2.42 & 11.63 & 1.46 & 1 & 2.81 & 82 & $11.3 \pm 0.8 / 45.4 \pm 3.1$ & $4.0 \pm 0.3 / 16.2 \pm 1.1^{\mathrm{d}}$ \\
\hline $20010302-05$ & $4.9(\mathrm{FW})$ & 2.21 & 10.67 & 1.58 & 1 & 2.78 & 33 & $17.1 \pm 0.6 / 71.6 \pm 7.6$ & $6.1 \pm 0.2 / 25.7 \pm 2.7^{d}$ \\
\hline 20010302-09 & $1.5(\mathrm{HW})$ & 1.87 & 9.48 & 1.49 & 12 & 2.26 & 38 & $16.8 \pm 2.7 / 53.1 \pm 4.8$ & $7.5 \pm 1.2 / 23.5 \pm 2.1$ \\
\hline $20010302-10$ & 1.3(HW) & 1.89 & 8.15 & 1.25 & 1 & 2.25 & 41 & $13.2 \pm 3.2 / 17.1 \pm 1.4$ & $5.9 \pm 1.4 / 26.6 \pm 2.0$ \\
\hline
\end{tabular}

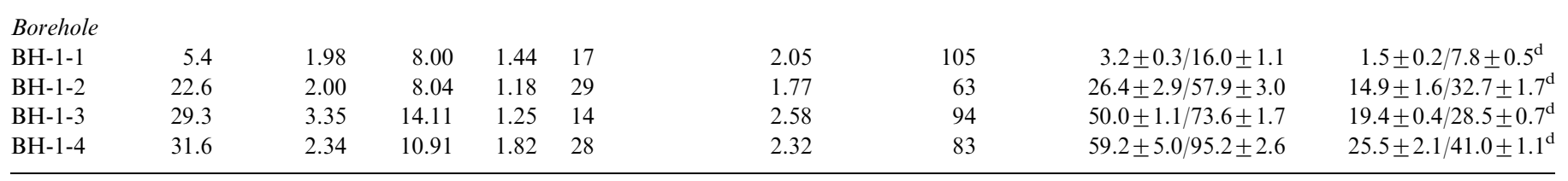

${ }^{\mathrm{a}} \mathrm{FW}$, footwall; HW, hanging wall.

${ }^{\mathrm{b}}$ Measurements by ICP-mass-spectrometry and XRF both provide precision better than $2 \%$, therefore the uncertainty for the total dose rate is less than $2 \%$.

${ }^{\mathrm{c}}$ Small aliquot for all the measurements.

${ }^{\mathrm{d}}$ The ages are used in the graph of Fig. 8.

the footwall but also the bedrock exposed at the bottom (Fig. 2).

\subsection{Borehole in the footwall}

A few months prior to the excavation of the Pineapple trench, a borehole was drilled in the footwall nearby and a $32 \mathrm{~m}$ long core collected. To acquire the long-term sedimentation rate of the footwall side, four OSL samples from depths of 5.4, 22.6, 29.3, and $31.6 \mathrm{~m}$ were obtained from the core. Following from the discussion concerning modern river sediments, samples affected by debrisflow influx may have an unbleached residue equivalent to ca. 2000 years. To reduce the influence of the unbleached residue, age computation of $5 \%$ minimum is a way to proceed (Olley et al., 1998, 1999). However, this method becomes less reliable for older samples because the residue becomes a smaller fraction of the total dose in the sample. Usually a sample younger than $10 \mathrm{ka}$ can be successfully corrected by this method. For samples older than $20 \mathrm{ka}$, using the total-mean method is more reliable. One criterion that can be considered to discriminate which method should be used if the age spans between 10 and $20 \mathrm{ka}$ is to check if there is significant positive skewness on the dose distribution (Fig. 6). Both the 5\% minimum and the totalmean age were calculated for the borehole samples: for the upper two (BH-1-1 and 2) by 5\% minimum and lower two (BH-1-3 and 4) by total mean. Sample BH-1-1 is younger than $10 \mathrm{ka}$ and its dose distribution shows significant positive skewness, and therefore the $5 \%$ minimum method is applied. Samples BH-1-3 and 4 are both old enough (roughly older than $20 \mathrm{ka}$ ). Their dose distributions do not show significant positive skewness. The total-mean method is therefore preferred. For sample BH-1-2, both of the above methods are tested, but the total-mean age will reverse the age order of the samples; thus the $5 \%$ minimum method is used to correct this age.

\section{Long-term slip rate of the segment at the Wufeng area}

Under the assumption that the long-term slip rate is constant at the timeframe of tens of thousand years, the slip rate of the fault segment was empirically examined at the trenching site. Moreover, if it is assumed that the fault is a plane and the vertical slip rate is the sine value of the net slip rate, the vertical slip rate can be considered as representative. Based on the geometry of the study site, the total vertical offset across the fault over a given time period can generally be represented by an altitude difference between footwall and hanging wall. It can be numerically expressed as a subtraction residual of footwall depth $(D f)$ plus the current scarp height $(S h)$ minus the hanging-wall depth $(D h)$ of a certain layer deposited in the past (Fig. 7). The vertical slip rate can then be derived by dividing the above residual by time (Eq. (1)). The footwall depth of a certain layer deposited $T$ years ago can be expressed as the footwall depositional rate times age (Eq. (2)). As a consequence, the vertical slip rate is composed of two components (Eq. (3)). The first is the depositional rate in the footwall, and the second one is a fraction of hangingwall layer depth and age. When the age is large enough, the second component will approach zero, because normally the hanging-wall thickness is relatively small for a thrust fault. In that case, the depositional rate in the footwall can 

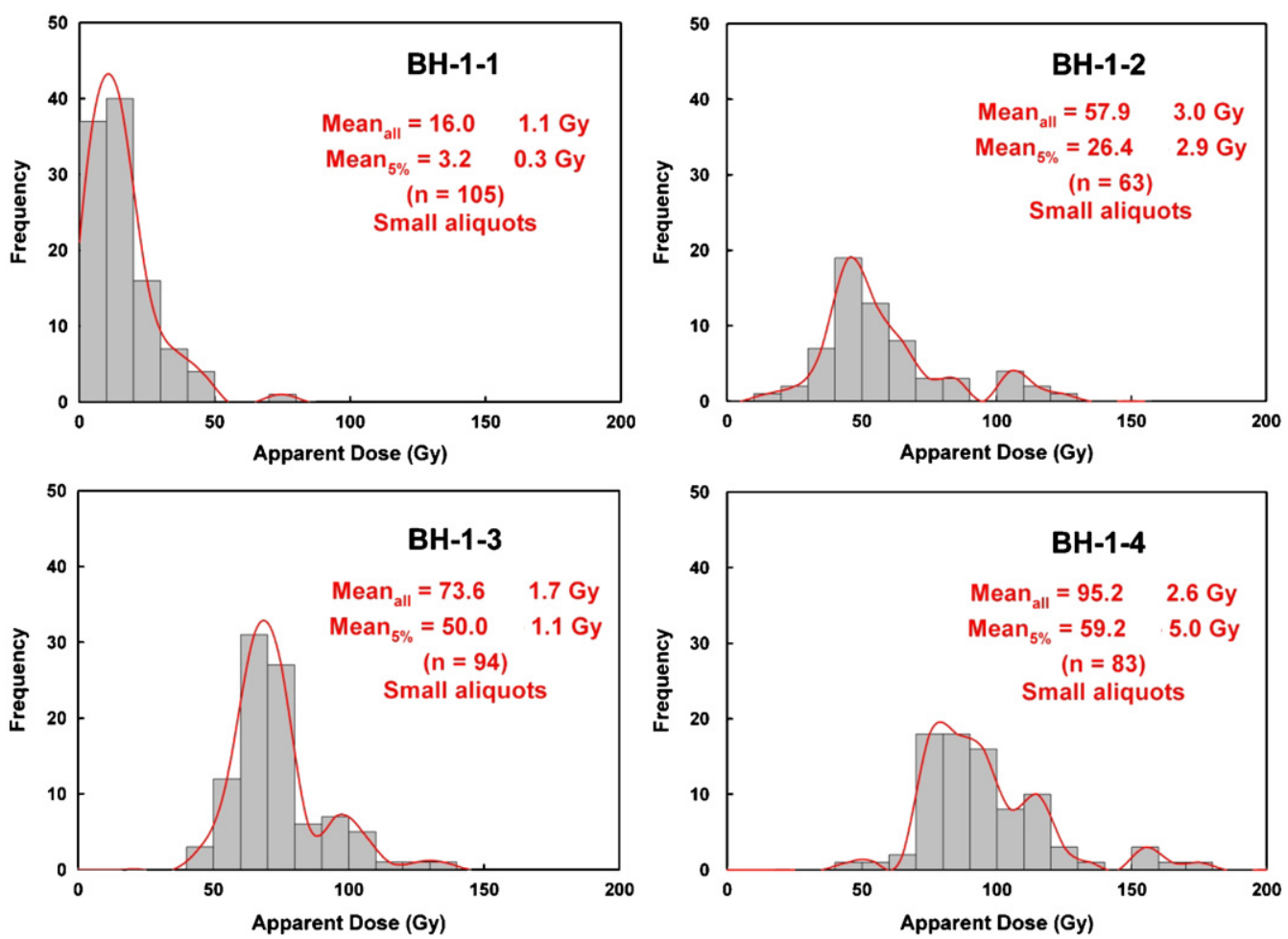

Fig. 6. Histograms showing the small-aliquot dose distributions of the samples collected from the footwall in a borehole close to the trenching site.

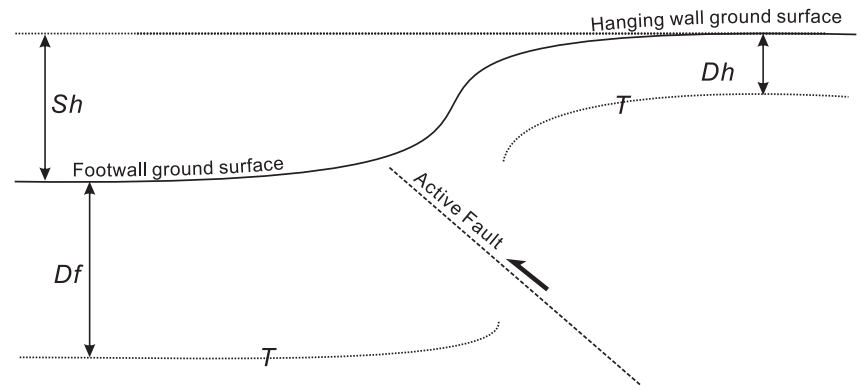

Fig. 7. Schematic profile across an active thrust fault. $S h$ is the height of the fault scarp. $D h$ and $D f$ represent the depths of sedimentary layer deposited $T$ years ago in the hanging wall and footwall, respectively. See text for the details.

represent the vertical long-term slip rate:

$V s r=(D f+S h-D h) / T$

$D f=D r T$

$V s r=D r+(S h-D h) / T$

where $V s r$ is the slip rate along the fault, $D f$ the depth of layer deposited $T$ years ago in the footwall (Fig. 7), Sh the current scarp height (Fig. 7), Dh the depth of layer deposited $T$ years ago in the hanging wall (Fig. 7), $T$ the depositional age of certain layer (Fig. 7), and $D r$ the depositional rate in the footwall.

In most trenches, however, the exposed depositional sequence is too short to derive a reliable long-term

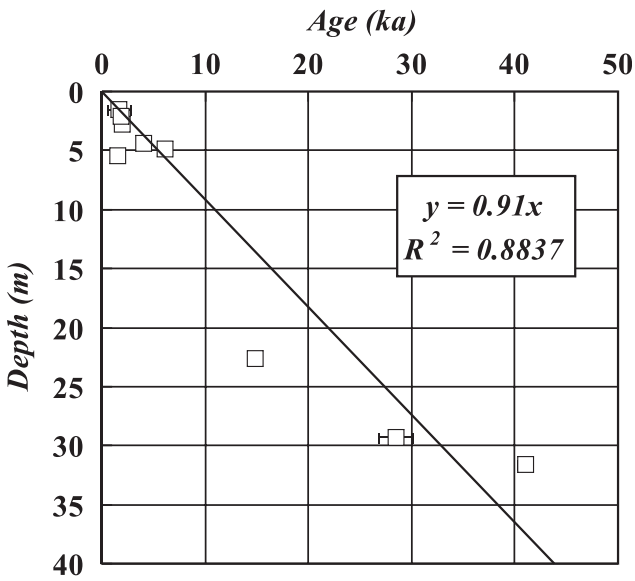

Fig. 8. Age-depth plot of the footwall samples from the trench and the adjacent borehole. The slope of the least-square regression line represents the long-term sedimentation rate.

depositional rate. For the purpose of time extension of the footwall sequence, four more OSL ages were obtained from a core drilled in the footwall a few hundred meters away. The histograms showing the small-aliquot dose distributions are shown in Fig. 6. The long-term depositional rate of $0.91 \mathrm{~m} / \mathrm{ka}$ can be derived from the leastsquare regression of all the OSL dates in a graph of age vs. depth (Fig. 8). This value is lower than the values (i.e., $2.8-11.7 \mathrm{~m} / \mathrm{ka}$ ) obtained at other places to the north and south (Y.G. Chen et al., 2003). The reason is probably that the "Pineapple" trenching site is located in a segment 
trending NE to SW, oblique to the general strike of the Chelungpu fault. Consequently, a certain amount of the total slip would be partitioned into strike slip but this cannot be distinguished in a two-dimensional trenching site.

\section{Paleoseismic events}

As expected, the trench logs can help identify the paleoseismic events by restoration of the layers across the
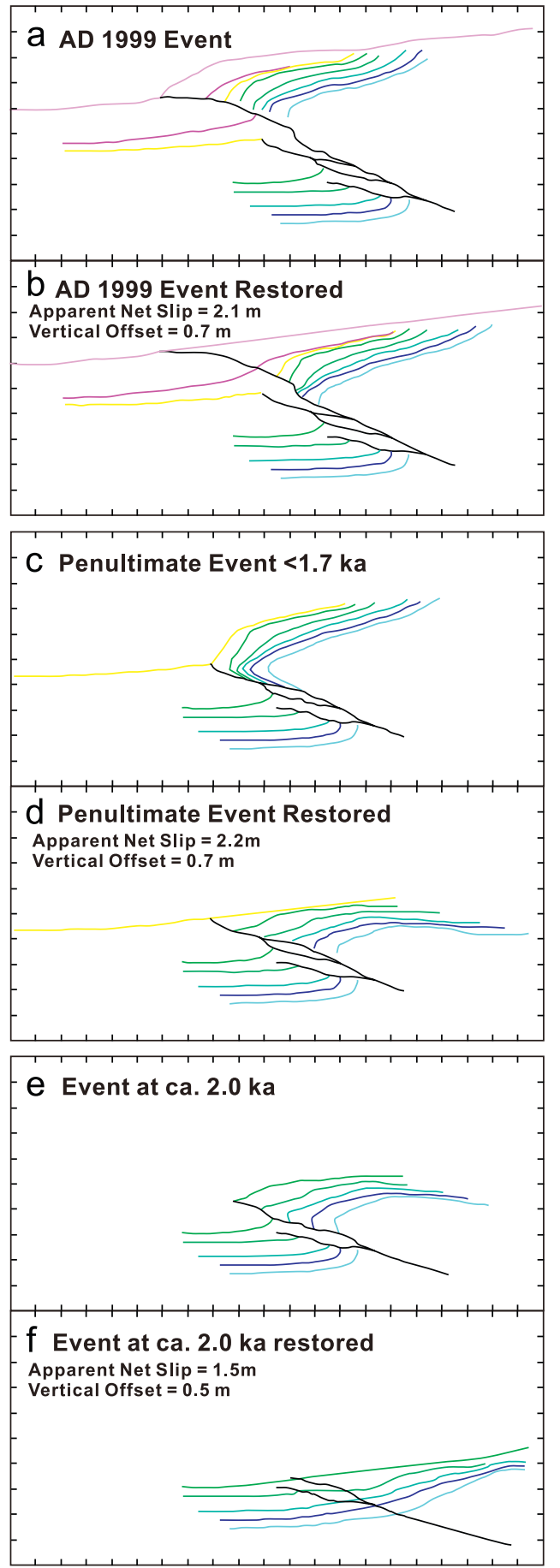

Fig. 9. Line-length restoration of the sediment layers identified in the Pineapple trench. Three events can be distinguished: the 1999 earthquake (a, b), an events $<1.7 \mathrm{ka}(\mathrm{c}, \mathrm{d})$, and an event of about $2 \mathrm{ka}(\mathrm{c}, \mathrm{f})$. fault scarp. Three events, including the 1999 rupture, were restored by the line-length method at the Pineapple site (Fig. 9). Based on the age results of both radiocarbon and OSL, the earliest event occurred at around $2 \mathrm{ka}$ (Fig. 2). This $2 \mathrm{ka}$ layer is a soil, in which abundant charcoals represent the termination of the environment. As to the penultimate event, there are insufficient reliable dates to constrain the age; so it can only be identified as being younger than the earliest event.

Restoration also yielded apparent event slips of 2.1, 2.2, and $1.5 \mathrm{~m}$ for earlier events. Since the trench $\log$ is a twodimensional data source, the calculated slips are actually apparent net slips. However, the vertical offsets would remain the same no matter how oblique the angle between the dipping direction and the profile orientation. The vertical offsets for these events are computed as $0.7,0.6$, and $0.5 \mathrm{~m}$, respectively, based on the corrections by the apparent dipping angle. In total, the cumulative vertical offset is ca. $1.8 \mathrm{~m}$ in the past 2000 years, which is consistent with the long-term value derived from the deposition rate.

\section{Conclusions}

1. In an area dominated by debris-flow deposits, 5\% minimum OSL ages derived from small $(3 \mathrm{~mm}$ in diameter) aliquot dose distributions measured using SAR seem to yield reliable results, in particular for the young samples (i.e., Holocene).

2. The OSL ages presented in this study allowed identification of unreliable radiocarbon dates and establishment of a numerical chronology for the sediments of the trench site.

3. The long-term vertical slip rate is ca. $0.91 \mathrm{~m} / \mathrm{ka}$ for the segment where the Pineapple trenching site is located. The cumulative vertical offset derived from the trench $\log$ for the past 2000 years is ca. $1.8 \mathrm{~m}$, similar to the amount computed from the long-term average.

\section{Acknowledgments}

This study is financially supported by the National Science Council and Central Geological Survey, Taiwan, ROC, under Grant numbers of NSC 93-2119-M-002-026 and 94-2119-M-002-002.

\section{References}

Aitken, M.J., 1985. Thermoluminescence Dating. Academic Press, London, p. 359.

Bollina, M.G., 1975. A review of recently active faults in Taiwan. United States Geological Survey Open-file Report 75-41, 58pp.

Bollina, M.G., 1977. Summary of Quaternary faulting and elevation changes in Taiwan. Memoirs of the Geological Society of China 2, $43-56$.

CGS, 1999. Investigation report of 921 earthquake geology and map of surface ruptures along the Chelungpu Fault during the 1999 Chi-Chi 
Earthquake. Central Geological Survey, Ministry of Economic Affairs, Taiwan, ROC (in Chinese).

Chen, W.S., Chen, Y.G., Chang, H.C., 2001a. Paleoseismic study of the Chelungpu fault in the Mingjian area. Western Pacific Earth Sciences 1 (3), 351-358

Chen, W.S., Chen, Y.G., Chang, H.C., Lee, Y.H., Lee, J.C., 2001b. Paleoseismic study of the Chelungpu fault in the Mingjian area. Western Pacific Earth Sciences 1 (4), 499-506.

Chen, W.S., Lee, K.J., Lee, L.S., Ponti, D.J., Prentice, C., Chen, Y.G., Chang, H.C., Lee, Y.H., 2004. Paleoseismology of the Chelungpu fault for the past 1900 years. Quaternary International 115/116, 167-176.

Chen, W.S., Lee, L.S., Lee, K.J., Yang, H.C., Yang, C.C., Yen, I.C., Chang, H.C., Ota, Y., Lin, C.W., Lin, W.S., Shih, T.S., Lu, S.T., 2005. Paleoseismology of the southern segment of the Chi-Chi earthquake rupture (the Chelungpu fault), central Taiwan: keys to fault behavior and characteristic earthquakes. In: Abstracts of the Hokudan International Symposium on Active Faulting, p. 17.

Chen, W.S., Lee, K.J., Lee, L.S., Streig, A.R., Rubin, C.M., Chen, Y.G., Yang, H.C., Chang, H.C., Lin, C.W., 2007. Paleoseismic evidence for coseismic growth-fold in the 1999 Chi-Chi earthquake and earlier earthquakes, central Taiwan. Journal of Asian Earth Sciences 31, 204-213.

Chen, Y.G., Chen, W.S., Lee, J.C., Lee, Y.H., Lee, C.T., Chang, H.C., Lo, C.H., 2001. Surface rupture of 1999 Chi-Chi earthquake yields insights on active tectonics of central Taiwan. Bulletin of the Seismological Society of America 91, 977-985.

Chen, Y.G., Chen, Y.W., Chen, W.S., Zhang, J.F., Zhao, H., Zhou, L.P., Li, S.H., 2003. Preliminary results of long-term slip rates of 1999 earthquake fault by luminescence and radiocarbon dating. Quaternary Science Reviews 22 (10-13), 1213-1221.

Chen, Y.W., Chen, Y.G., Murray, A.S., Lai, D.J., 2003. Luminescence dating of neotectonic activity on the southwestern coastal plain, Taiwan. Quaternary Science Reviews 22 (10-13), 1223-1229.

Ho, C.S., 1988. An Introduction to the Geology of Taiwan: Explanatory Text for the Geologic Map of Taiwan, second ed. Central Geological
Survey, Ministry of Economic Affairs, Taiwan, ROC, 164pp. (Scale $1: 500,000)$

Lin, C.W., Chang, H.C., Lu, S.T., Shih, T.S., Huang, W.J., 2000. An Introduction to the Active Faults of Taiwan: Explanatory Text of the Active Fault Map of Taiwan, second ed. In: Special Publication 13, Central Geological Survey, Taiwan, 122pp. (in Chinese with English abstract, Scale 1:500,000).

Ma, K.F., Lee, C.T., Tsai, Y.B., Shin, T.C., Mori, J., 1999. The Chi-Chi, Taiwan earthquake: large surface displacements on an inland thrust fault. EOS Transactions 80, 605-611.

Murray, A.S., Wintle, A.G., 2000. Luminescence dating of quartz using an improved single-aliquot regenerative-dose protocol. Radiation Measurements $32,57-73$.

Olley, J.M., Caitcheon, G., Murray, A.S., 1998. The distribution of apparent dose as determined by optically stimulated luminescence in small aliquots of fluvial quartz: implications for dating young sediments. Quaternary Science Reviews (Quaternary Geochronology) $17,1033-1040$

Olley, J.M., Caitcheon, G.G., Roberts, R.G., 1999. The origin of dose distributions in fluvial sediments, and the prospect of dating single grains from fluvial deposits using optically stimulated luminescence. Radiation Measurements 30, 207-217.

Shyu, J.B.H., Sieh, K., Chen, Y.G., Liu, C.S., 2005. The neotectonic architecture of Taiwan and its implications for future large earthquakes. Journal of Geophysical Research 110, B08402.

Sieh, K., 1984. Lateral offsets and revised dates of large earthquakes at Pallett Creek, California. Journal of Geophysical Research 89, 7641-7670.

Teng, L.S., 1990. Geotectonic evolution of late Cenozoic arc-continent collision in Taiwan. Tectonophysics 183, 57-76.

Thomsen, K.J., Jain, M., Bøtter-Jensen, L., Murray, A.S., Jungner, H., 2003. Variation with depth of dose distributions in single grains of quartz extracted from an irradiated concrete block. Radiation Measurements 37, 315-321. 